\title{
MET in gastric carcinomas: comparison between protein expression and gene copy number and impact on clinical outcome
}

\author{
HE Lee ${ }^{1,2}$, MA Kim ${ }^{1,2}$, HS Lee ${ }^{2,3}$, E-J Jung ${ }^{2}$, H-K Yang ${ }^{4}$, BL Lee ${ }^{5}$, Y-J Bang ${ }^{6}$ and WH Kim ${ }^{*, 1,2,5}$ \\ 'Department of Pathology, Seoul National University Hospital, 28 Yeongeon-dong, Jongno-gu, Seoul I l 0-799, Korea; ${ }^{2}$ Department of Pathology, Seoul \\ National University College of Medicine, Seoul, Korea; ${ }^{3}$ Department of Pathology, Seoul National University Bundang Hospital, Seongnam, Korea; \\ ${ }^{4}$ Department of Surgery, Seoul National University College of Medicine, Seoul, Korea; ${ }^{5}$ Cancer Research Institute, Seoul National University College of \\ Medicine, Seoul, Korea; ${ }^{6}$ Department of Medicine, Seoul National University College of Medicine, Seoul, Korea
}

BACKGROUND: The aim of this study was to compare gene copy number (GCN) and protein expression of MET and to evaluate their prognostic roles in gastric carcinomas.

METHODS: MET protein expression and gene amplification (GA) status were determined by immunohistochemistry (IHC) and silver in-situ hybridisation (SISH), respectively, in a large series of gastric carcinoma.

RESULTS: Protein overexpression was observed in 104 of 438 cases, with $\mathrm{HCC} 2+$ in 94 and $\mathrm{HC} 3+$ in 10 , and high polysomy of chromosome 7 and GA were found in 61 and 13 of 38 I, respectively. Direct comparison revealed a significant correlation between high level of protein expression and increased GCN. All cases with GA showed protein overexpression. Furthermore, all with IHC $3+$ showed GA except I, even which could be categorised as GA according to the ASCO/CAP guideline for human epidermal growth factor receptor 2 assessment. IHC $3+$ and GA were significantly associated with poor prognosis.

CONCLUSION: MET IHC reflects well on GA, and therefore, it could be a primary screening test for patient selection for anti-MET therapy if GA is a major determinant of drug responsiveness. Also, the prognostic role of MET indicates that anti-MET therapy is a very promising modality in adjuvant treatment for gastric cancer.

British Journal of Cancer (2012) 107, 325-333. doi:I0.1038/bjc.2012.237 www.bjcancer.com

Published online 29 May 2012

(C) 2012 Cancer Research UK

Keywords: stomach neoplasm; MET; immunohistochemistry; silver in-situ hybridisation; gene amplification

Molecular targeting on oncogene is a new therapeutic modality now under intense investigation. Recent clinical success of human epidermal growth factor receptor 2 (HER2) inhibitors in treating metastatic gastric cancers (Bang et al, 2010) have raised hopes that the identification of other deregulated oncogenic pathways in gastric cancer will lead to new therapeutic options for gastric cancer. MET, the hepatocyte growth factor receptor, is another receptor tyrosine kinase overexpressed and activated in a subset of human epithelial malignancy. An activated MET signalling pathway via gain-offunction mutation or amplification of the MET gene promotes tumour cell growth, survival, migration, and invasion as well as tumour angiogenesis (Liu et al, 2010). MET gene mutation has been found mainly in hereditary papillary renal cell carcinoma (Schmidt et al, 1997) and in a subset of lung cancer (Ma et al, 2003). Previous studies described MET gene amplification (GA) in 4\% of non-smallcell lung cancers (Cappuzzo et al, 2009; Go et al, 2010), in $4 \%$ of oesophageal cancer (Miller et al, 2005), and in endometrial cancer (Samuelson et al, 2008). In gastric cancer, it has been reported that $M E T$ amplification was found in $0-23 \%$ of gastric cancers, and MET overexpression and/or GA was associated with advanced disease stage and/or worse clinical outcome (Hara et al, 1998; Nakajima et al, 1999; Huang et al, 2001; Amemiya et al, 2002; Graziano et al, 2011; Janjigian et al, 2011; Lee et al, 2011; Lennerz et al, 2011; Zhao et al, 2011; Toiyama et al, 2012). However, most studies were limited by

*Correspondence: Dr WH Kim; E-mail: woohokim@snu.ac.kr Received 3 January 2012; revised 23 April 2012; accepted 2 May 2012; published online 29 May 2012 small cohort sizes, and there were few studies performed in a large, unselected, consecutively accrued gastric cancer cohort.

Based on the strong association of abnormal MET signalling with human cancers, tyrosine kinase inhibitors and therapeutic monoclonal antibodies that antagonise MET activation have been actively developed (Liu et al, 2010). Furthermore, preclinical findings indicate that MET pathway may represent a therapeutic target for gastric carcinoma by showing that gastric cancer cells with high-level GA of $M E T$ are extraordinarily susceptible to the specific MET tyrosine kinase inhibitor PHA-665752 (Smolen, 2006). More recently, phase I and phase II clinical trials with MET inhibitors are ongoing for gastric cancer patients (Cecchi et al, 2010; Liu et al, 2010), and among others, some inhibitors have been found to produce tumour regression in their clinical trials (Lennerz et al, 2011; Yap et al, 2011). However, the correlation between MET status and treatment response, and the optimal method to determine MET status in the tumours are undefined.

This study was designed to investigate the association between MET protein expression evaluated by immunohistochemistry (IHC) and gene copy number (GCN) evaluated by silver in-situ hybridisation (SISH) and to assess whether MET status determined by these two methods was associated with prognosis in a large series of consecutive gastric carcinoma cases.

\section{PATIENTS AND METHODS}

\section{Patients}

This retrospective study was conducted in a cohort of 438 gastric cancer patients that received a surgical resection of primary gastric 
carcinoma at Seoul National University Hospital, Seoul, Korea, in 2004. The only criteria used for patient selection included the availability of tumour tissue from primary gastric carcinoma (exclusion of mucosal cancer with the largest tumour diameter of $\leqslant 1.5 \mathrm{~cm}$ ) and survival data. Paraffin-embedded tumour specimens were used to construct a tissue microarray. Age, gender, tumour location, WHO (Fenoglio-Preiser et al, 2000) and Lauren's classification, pTNM (pathologic Tumor-Node-Metastasis) stage (by seventh UICC/AJCC), and lymphatic invasion were evaluated by reviewing medical charts, pathological records, gross photographs, and glass slides. Median follow-up period of patients was 54 (range, 1-99) months. No patient received preoperative chemoradiotherapy, and patients with stage II, III, or IV disease received postoperative chemotherapy using fluorouracil (5FU)based regimen (5FU alone, $5 \mathrm{FU}+$ mitomycin $\mathrm{C}$, or $5 \mathrm{FU}+$ cisplatin). The study protocol was reviewed and approved by the Institutional Review Board of Seoul National University Hospital.

\section{Tissue array methods}

Core tissue biopsies ( $2 \mathrm{~mm}$ in diameter) were taken from individual formalin-fixed, paraffin-embedded gastric carcinomas (donor blocks) and arranged in a new recipient paraffin block (tissue array block) using a trephine apparatus (Superbiochips Laboratories, Seoul, Korea). Because we have previously shown excellent agreement between the staining results of different intratumoural areas in gastric carcinomas (Lee et al, 2001), a core was sampled from each case.

\section{Immunohistochemistry}

Immunohistochemical staining was performed using an automatic immunostainer (BenchMark XT, Ventana Medical Systems, Tucson, AZ, USA), according to manufacturer's instructions. The primary antibody used was anti-total MET (SP44; rabbit monoclonal; prediluted; Ventana Medical Systems) antibody.

By using the DAKO HercepTest guideline (DAKO, Glostrup, Denmark), a semiquantitative approach was used to generate a score for each tissue core as follows: no membrane staining or membrane staining in $<10 \%$ of tumour cells (score 0 ), faint/barely perceptible partial membrane staining in $>10 \%$ of tumour cells (score $1+$ ), weak-to-moderate staining of the entire membrane in $>10 \%$ of tumour cells (score $2+$ ), and strong staining of the entire membrane in $>10 \%$ of tumour cells (score $3+$ ). Scores of 0 and $1+$ were considered as negative for MET overexpression, and scores of $2+$ and $3+$ were considered as positive. The IHC scoring was performed microscopically by two independent pathologists (WHK and HEL) unaware of the clinical details of individual patients. The case-by-case final consensus result was discussed and determined in a common session.

\section{Dual-colour SISH}

Automated SISH was performed on a Ventana BenchMark XT (Ventana Medical Systems). INFORM MET DNA Probe (Ventana Medical Systems) and INFORM Chromosome 7 Probe (Ventana Medical Systems) were visualised on the same slides, following manufacturer's protocols.

Signals were enumerated in at least 100 tumour nuclei per core, using a light microscope with objectives from $\times 20$ to $\times 60$. In some nuclei, clusters of dots representing many copies of MET gene were apparent. According to the interpretive guide for Ventana INFORM HER2 DNA probe staining of breast carcinoma (Ventana Medical Systems), a small cluster of multiple signals was counted as 6 signals, and a large cluster as 12 signals.

By using the University of Colorado Cancer Center (UCCC) criteria for epidermal growth factor receptor gene (Cappuzzo et al, 2005), the MET gene status was classified into six groups as follows: (i) disomy ( $\leqslant 2$ copies in $\geqslant 90 \%$ of cells); (ii) low trisomy ( $\leqslant 2$ copies in $\geqslant 40 \%$ of cells, 3 copies in $10-40 \%$ of cells, $\geqslant 4$ copies in $<10 \%$ of cells); (iii) high trisomy ( $\leqslant 2$ copies in $\geqslant 40 \%$ of cells, 3 copies in $\geqslant 40 \%$ of cells, $\geqslant 4$ copies in $<10 \%$ of cells); (iv) low polysomy ( $\geqslant 4$ copies in $10-40 \%$ of cells); (v) high polysomy ( $\geqslant 4$ copies in $\geqslant 40 \%$ of cells); and (vi) GA (defined by the presence of tight $M E T$ gene clusters and a ratio of $M E T$ geneto-chromosome of $\geqslant 2$ or $\geqslant 15$ copies of $M E T$ per cell in $\geqslant 10 \%$ of analysed cells). High polysomy and GA were regarded as a positive SISH result, and others as a negative.

\section{Laser-capture microdissection}

We collected tumour cells from tissue array slides. Briefly, $4-\mu \mathrm{m}$ paraffin-embedded tissue sections were deparaffinised with xylene. Rehydrated using graded ethanol series, stained with haematoxylin and eosin, rinsed in tap water, and finally immersed in $100 \%$ ethanol. After drying, areas of interest were identified. Tumour cells were selectively microdissected using a laser microdissection device (ION LMD, Jung Woo International, Co, Seoul, Korea). For DNA extraction, dissected cells were collected into $50 \mu \mathrm{l}$ of DNA extraction buffer, which was composed of $0.5 \%$ Tween-20, proteinase $\mathrm{K}\left(20 \mathrm{mg} \mathrm{ml}^{-1}\right)$, and 50\% Chelex-100 (Sigma Chemical Co, St Louis, MO, USA).

\section{Quantitative real-time PCR}

MET DNA amounts were determined using an Applied Biosystems 7500 Real-Time PCR System (Applied Biosystems, Foster City, CA, USA), and the data were analysed using SDS (Ver. 1.4) software (Applied Biosystems). Quantitative real-time PCR (qPCR) of MET was carried out using a Taqman Copy Number Assay (Assay ID, Hs02884964_cn; Applied Biosystems). RNaseP served as an endogenous control. A standard curve was generated for each gene with serial dilutions of standard DNA $(100,50,25,12.5$, and $6.25 \mathrm{ng}$ ). The qPCR was done using $50 \mathrm{ng}$ of template DNA from microdissected gastric carcinoma. Each analysis included a control without template DNA. After PCR amplification, a melting curve was generated for all PCR products to check PCR specificities. Normalised gene ratios were interpreted as follows: $<2=$ negative for GA and $\geqslant 2.0=$ positive for GA. All results were normalised $v s$ respective amounts of RNaseP DNA (Applied Biosystems).

\section{Statistical analyses}

The $\chi^{2}$-test or Fisher's exact test (two-sided) was used to determine the nature of the correlations between protein expression or GCN and clinicopathologic parameters. The comparison of $\mathrm{qPCR}$ values between MET-amplified and MET-non-amplified groups was accomplished by Mann-Whitney $U$-test. The correlations between SISH and IHC or qPCR results were analysed using the Spearman rank method. Survival curves were plotted using the Kaplan-Meier product-limit method, and significance of differences between these curves was determined using the log-rank test. Multivariate survival analysis was performed using the Cox proportional hazards model. Results were considered significant when $P$-values were $<0.05$. All statistical analyses were conducted using the PASW 19.0 statistical software program (IBM SPSS Statistics, Chicago, IL, USA).

\section{RESULTS}

\section{MET protein expression}

MET protein expression was evaluated by IHC in 438 cases; 165 (37.7\%), $169(38.6 \%), 94(21.5 \%)$, and $10(2.3 \%)$ cases were scored as $0,1+, 2+$, and $3+$, respectively (Figure $1 \mathrm{~A}-\mathrm{C}$ ). A statistically significant difference in the MET expression was observed across the Lauren histological subtypes $(P<0.001$; Table 1$)$. Whereas IHC 

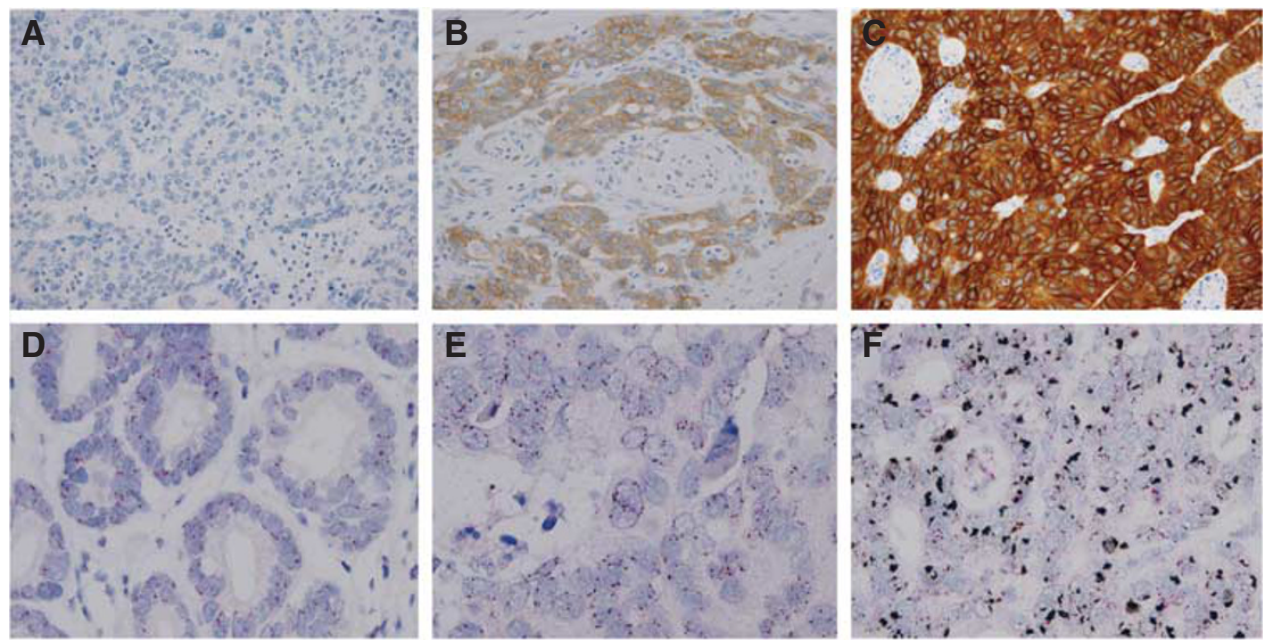

Figure I Representative microphotographs of MET IHC (A-C) and SISH (D-F). Cases of no membranous staining (IHC 0; A), weak-to-moderate staining of the entire membrane $(\mathrm{IHC} 2+; \mathbf{B})$, and strong staining of the entire membrane $(\mathrm{IHC} 3+; \mathbf{C})$ by $I \mathrm{HC}$, and cases of disomy $(\mathbf{D})$, high polysomy $(\mathbf{E})$, and GA $(\mathbf{F})$ by SISH are shown.

$3+$ cases more frequently showed diffuse- or mixed-type (70\%), IHC $2+$ cases more frequently had intestinal-type cancers $(67 \%)$. Among 181 intestinal-type cancers, 35\% showed IHC $2+$, which was significantly different from the expression observed in diffuseor mixed-type cancers (12\%). Furthermore, 63\% (19 out of 30) of well-differentiated tubular adenocarcinoma cases were scored as $2+$. Conversely, diffuse- or mixed-type cancers were mostly IHC negative $(85 \%)$ in contrast to intestinal-type cancers $(64 \%)$. However, the frequency of IHC $3+$ was higher in diffuse- or mixed-type cancers than in intestinal-type cancers $(2.7 \%$ vs $1.7 \%)$. Patients with IHC $3+$ had significantly more frequent lymph-node metastases $(P=0.008)$ and more advanced TNM stages $(P=0.024)$ than the remaining cases. On the other hand, patients with IHC $2+$ showed significantly less advanced TNM stages than those with IHC negative $(P<0.001)$.

\section{MET GCN}

MET GCN was evaluated by SISH in 381 cases, and the SISH patterns are illustrated in Figure 1D-F. The average GCN per cell and the MET-to-chromosome 7 ratio for the SISH patterns are listed in Supplementary Table S1. In all, 133 (34.9\%), 97 (25.5\%), $77(20.2 \%), 61(16.0 \%)$, and $13(3.4 \%)$ patients showed disomy, low trisomy, low polysomy, high polysomy, and GA, respectively. High trisomy was not detected. Among 13 patients showing MET GA, 3 had a low level of amplification (gene-to-chromosome ratio ranging between 2.1 and 3.0), and 10 had a high level of amplification (gene-to-chromosome ratio $>3$ ), with the average per cell for the MET gene copies ranging from 5.6 to 41.6 , and the ratio of gene-to-chromosome ranging from 2.1 to 19.3.

The distribution of the SISH patterns according to various clinicopathologic parameters is summarised in Table 1. Correlation between GA and Lauren type was not found; 6 of 13 cases with GA were intestinal-type and 7 were diffuse- or mixed-type cancers. However, high polysomy cases more frequently showed intestinaltype than diffuse- or mixed-type cancers. Among 163 intestinaltype cancers, $23 \%$ had high polysomy, which was significantly different from the gene status observed in diffuse- or mixed-type cancers $(11 \%)$. The frequency of GA was similar between the two groups (3.7 and 3.2\%). Patients with MET GA showed more frequent distant metastasis $(P=0.031)$ and more advanced TNM stage $(P=0.018)$ than those without MET GA. On the other hand, the TNM stage was not significantly different between high polysomy and SISH-negative cases.

MET GCN was also assessed by qPCR, which was performed on all 13 SISH-determined, MET-amplified gastric carcinoma tissues and on 13 non-amplified tissues. Calculated MET/RNaseP ratios being indicative of relative MET GCNs were higher in amplified cases than in non-amplified cases (median (interquartile range), 4.49 (1.94-13.29) vs $1.04(0.76-1.44) ; P<0.001)$ (Supplementary Figure S1). Also, scatter plot depicting the association between relative MET GCNs determined by qPCR and the GCNs by SISH indicated that there was a strong positive correlation $(r=0.760$; $P<0.001$ ) (Figure 2).

\section{Association between MET protein expression and GCN}

The correlation between MET protein expression and GCN by SISH is presented in Table 2 and Figure 3. There was a positive correlation between high protein expression and increased GCN $(r=0.31 ; P<0.001)$. Among the 283 patients with a negative MET expression, 249 patients (88.0\%) had SISH negative, and the rest of the patients $(12.0 \%)$ had high polysomy, and remarkably, none showed GA. In contrast, among the 88 patients with MET IHC $2+$, $26(29.5 \%)$ and $4(4.5 \%)$ had high polysomy and GA, respectively. Also, all patients with IHC $3+(n=10)$ had GA except 1 , who had the average per cell for MET gene copies of 7.8 (range, 2-24), ratio of gene-to-chromosome of 1.56 , and tumour cells $\geqslant 15$ copies of $M E T$ per cell in $8 \%$ of analysed cells, and therefore, the case was categorised as high polysomy according to the UCCC criteria.

Patients with MET SISH negative tended to have low IHC scores, whereas the IHC score increased when SISH abnormalities became more severe (Figure 3). Specifically, in the comparison of total cases, the higher was the MET GCN, the lower was the frequency of IHC 0 and the higher was that of IHC $2+$ and IHC $3+$. That of IHC $1+$ was similar among the groups of SISH pattern. Notably, among 13 cases of GA, $4(30.8 \%)$ and $9(69.2 \%)$ showed IHC $2+$ and IHC $3+$, respectively, whereas none had IHC 0 or IHC $1+$ (Figure 3A). These results suggested that a low number of MET gene copies per cell, including disomy and trisomy, had not influenced the level of protein expression, whereas a high number of gene copies, both as high polysomy and as GA, had an impact on the protein level.

When the association between protein expression and gene levels was also investigated according to the Lauren histologic 
Table I Clinicopathologic characteristics of gastric carcinoma patients according to MET status

\begin{tabular}{|c|c|c|c|c|c|c|c|c|}
\hline & \multicolumn{3}{|c|}{ MET IHC } & \multirow[b]{3}{*}{$P$-value } & \multicolumn{3}{|c|}{ MET SISH } & \multirow[b]{3}{*}{$P$-value } \\
\hline & \multirow{2}{*}{$\begin{array}{l}\text { Negative } \\
0 \text { or I + } \\
(n=334 \\
(76.3 \%))\end{array}$} & \multicolumn{2}{|c|}{ Positive } & & \multirow{2}{*}{$\begin{array}{c}\text { Negative } \\
\text { DS, LT, or } \\
\text { LP }(n=307 \\
(80.6 \%))\end{array}$} & \multicolumn{2}{|c|}{ Positive } & \\
\hline & & $\begin{array}{c}2+ \\
(n=94 \\
(21.5 \%))\end{array}$ & $\begin{array}{c}3+ \\
(n=10 \\
(2.3 \%))\end{array}$ & & & $\begin{array}{c}\text { HP } \\
(n=6 I \\
(16.0 \%))\end{array}$ & $\begin{array}{c}\text { GA } \\
(n=13 \\
(3.4 \%))\end{array}$ & \\
\hline Age (mean \pm s.d., years) & $56.8 \pm 12.8$ & $59.3 \pm 12.1$ & $66.5 \pm 11.3$ & 0.018 & $57.4 \pm 12.6$ & $58.8 \pm 13.3$ & $65.5 \pm 12.5$ & 0.114 \\
\hline $\begin{array}{l}\text { Lauren, } n(\%) \\
\text { Intestinal } \\
\text { Diffuse of mixed }\end{array}$ & $\begin{array}{l}115(34.4) \\
219(65.6)\end{array}$ & $\begin{array}{l}63(67.0) \\
31(33.0)\end{array}$ & $\begin{array}{l}3(30.0) \\
7(70.0)\end{array}$ & $<0.001$ & $\begin{array}{l}120(39.1) \\
187(60.9)\end{array}$ & $\begin{array}{l}37(60.7) \\
24(39.3)\end{array}$ & $\begin{array}{l}6(46.2) \\
7(53.8)\end{array}$ & 0.008 \\
\hline $\begin{array}{l}\text { Tumour invasion, } n \text { (\%) } \\
\text { EGC } \\
\text { AGC }\end{array}$ & $\begin{array}{r}72(21.9) \\
261(78.1)\end{array}$ & $\begin{array}{l}45(47.9) \\
49(52.1)\end{array}$ & $\begin{array}{l}0(0) \\
10(100.0)\end{array}$ & $<0.001$ & $\begin{array}{r}95(30.9) \\
212(69.1)\end{array}$ & $\begin{array}{l}15(24.6) \\
46(75.4)\end{array}$ & $\begin{array}{r}2(15.4) \\
11(84.6)\end{array}$ & 0.323 \\
\hline $\begin{array}{l}\text { Distant metastasis, n (\%) } \\
\text { No } \\
\text { Yes }\end{array}$ & $\begin{array}{r}290(86.8) \\
44(13.2)\end{array}$ & $\begin{array}{r}89(94.7) \\
5(5.3)\end{array}$ & $\begin{array}{l}6(60.0) \\
4(40.0)\end{array}$ & 0.003 & $\begin{array}{r}276(89.9) \\
31(10.1)\end{array}$ & $\begin{aligned} 55 & (90.2) \\
6 & (9.8)\end{aligned}$ & $\begin{array}{l}9(69.2) \\
4(30.8)\end{array}$ & 0.060 \\
\hline $\begin{array}{l}\text { TNM stage, n (\%) } \\
\text { I } \\
\| \\
\text { III } \\
\text { IV }\end{array}$ & $\begin{array}{r}98(29.3) \\
79(23.7) \\
113(33.8) \\
44(13.2)\end{array}$ & $\begin{array}{c}48(51.1) \\
21(22.3) \\
20(21.3) \\
5(5.3)\end{array}$ & $\begin{array}{l}0(0) \\
1(10.0) \\
5(50.0) \\
4(40.0)\end{array}$ & $<0.001$ & $\begin{array}{r}116(37.8) \\
67(21.8) \\
93(30.3) \\
31(10.1)\end{array}$ & $\begin{array}{c}19(31.1) \\
17(27.9) \\
19(31.1) \\
6(9.8)\end{array}$ & $\begin{array}{l}3(23.1) \\
1(7.7) \\
5(38.5) \\
4(30.8)\end{array}$ & 0.193 \\
\hline
\end{tabular}

Abbreviations: $\mathrm{AGC}=$ advanced gastric carcinoma; $\mathrm{DS}=$ disomy; $\mathrm{EGC}=$ early gastric carcinoma; $\mathrm{GA}=$ gene amplification; $\mathrm{HP}=$ high polysomy; $1 \mathrm{HC}=$ immunohistochemistry $\mathrm{LN}=$ lymph node; $\mathrm{LP}=$ low polysomy; $\mathrm{LT}=$ low trisomy; s.d. = standard deviation; $\mathrm{SISH}=$ silver in-situ hybridisation; $\mathrm{TNM}=$ Tumor-Node-Metastasis. $\chi^{2}$ or Fisher's exact test was used in each analysis except for the analysis of age factor (analysis of variance).

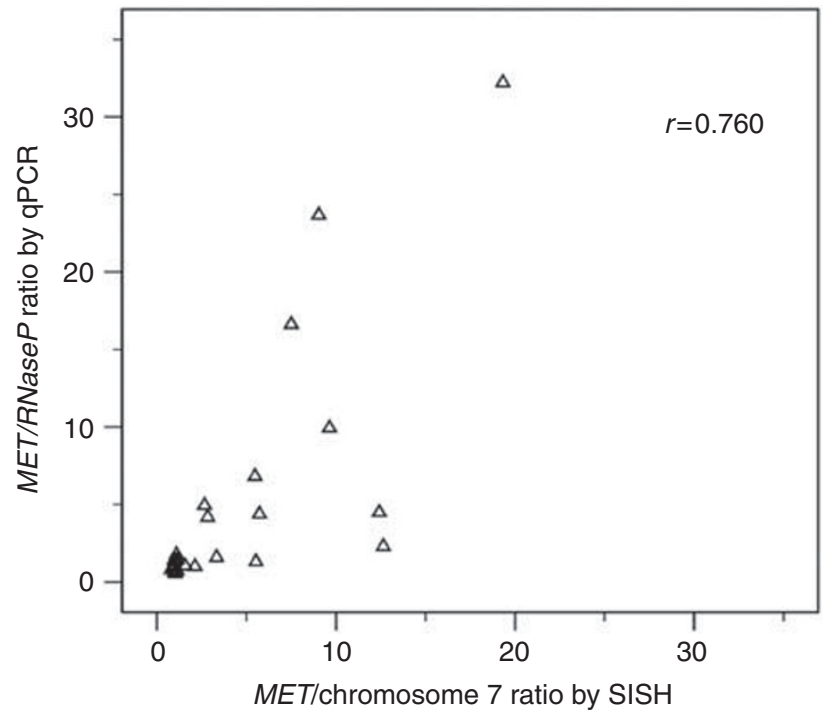

Figure 2 Scatter plot depicting the association between relative MET gene copy numbers determined by GPCR and SISH. There was a strong positive correlation between the MET/RNaseP ratio by qPCR and the METI chromosome 7 ratio by $\mathrm{SISH}(r=0.760 ; P<0.00 \mathrm{I})$.

subtype, it was found that the high number of gene copies per cell was closely associated with high protein expression independent of histology $(r=0.35, P<0.001$ in intestinal-type; $r=0.19, P=0.004$ in diffuse- or mixed-type cancers). Interestingly, in the GA group of intestinal-type cancers, the frequency of IHC $2+$ was higher than that of IHC $3+(66.7 \%$ vs $33.3 \%)$. In contrast, in the cases of diffuse- or mixed-type cancers, all cases showing GA showed IHC $3+$ and vice versa (Figure $3 \mathrm{~B}$ and $\mathrm{C}$ ).

\section{Prognostic implications of MET protein expression and GCN}

Kaplan-Meier survival curves for patients in the different categories of MET protein expression are shown in Figure 4. Whereas the group of IHC $3+$ had a shorter overall survival (OS) time than that of IHC negative, the group of IHC $2+$ had a longer OS time, which was independent of the Lauren histologic subtype. In the subgroup analyses of disease stage, there was no difference in OS among the three IHC score groups in stage I-II. In stage III-IV, survival differences were found among the IHC score groups, although they did not reach statistical significances. In multivariate analyses, MET protein expression level was not a significant independent prognostic factor (data not shown).

Kaplan-Meier survival curves for patients in different categories of MET gene level are shown in Figure 5. Survival, as a function of MET GCN, was found to decrease with increasing GCN. However, the group of high polysomy tended to have a longer OS time than that of low polysomy although it was not a statistically significant difference. Also, when the patients were divided into SISH negative, high polysomy, and GA, the patient OS time tended to decrease with increasing copy number. In the subgroup analysis of diffuse- or mixed-subtype cancers, the trend was more profound. 
Table 2 Associations between MET protein expression and MET gene copy number

\begin{tabular}{|c|c|c|c|c|c|c|}
\hline & \multicolumn{5}{|c|}{ MET SISH patterns } & Total \\
\hline \multicolumn{7}{|l|}{ MET IHC } \\
\hline I, n (\%) & $60(39.2)$ & $38(24.8)$ & $35(22.9)$ & $20(13.1)$ & $0(0)$ & $153(100)$ \\
\hline $2, n(\%)$ & $17(19.3)$ & $20(22.7)$ & $21(23.9)$ & $26(29.5)$ & $4(4.5)$ & $88(100)$ \\
\hline $3, n(\%)$ & $0(0)$ & $0(0)$ & $0(0)$ & I (10.0) & $9(90.0)$ & $10(100)$ \\
\hline
\end{tabular}

Abbreviations: $\mathrm{IHC}=$ immunohistochemistry; $\mathrm{SISH}=$ silver in-situ hybridisation.

On the other hand, in the subgroup of intestinal subtype, the high polysomy group tended to have a longer survival time than the SISH-negative group, although it was not statistically significant. Whereas this association was further confirmed when survival analysis was limited to patients with stage III and IV disease, it was not found when the analysis was limited to those with stage I and II disease. The hazard ratio was calculated for the MET SISH result as shown in Supplementary Table S2, after adjusting for the most commonly used clinical prognostic markers including tumour invasion, lymph-node metastasis, distant metastasis, residual tumour, and Lauren histologic subtypes, which were all found to have prognostic significance by univariate analyses. MET GA was associated with a significantly increased hazard ratio of 2.27 (95\% CI, 1.05-4.93) compared with patients with tumours not having GA independent of other classical prognostic factors.

Associations between MET protein expression or gene status and disease-free survival (DFS) were shown in Supplementary Figure S2 and S3, respectively. High protein expression and GA were related to the shorter DFS time. In addition, IHC $3+$ and GA were found to be independent negative prognostic factors for DFS in multivariate analyses (Supplementary Tables S3 and S4).

\section{DISCUSSION}

The need for accurate detection of the MET alteration has now become even more important, because therapeutic decisions for patients as well as determining patient prognosis are possibly dependent on this information. In the present study, we performed direct comparison of MET GCN per cell detected by SISH with MET protein expression evaluated by IHC and have shown that there was a significant correlation between increased GCN and the high level of protein expression. Furthermore, we demonstrated that strong protein expression (IHC $3+$ ) or GA of $M E T$ was significantly associated with patient poor survival in a large, unselected, consecutively accrued gastric cancer cohort.

In-situ-based technologies such as IHC and SISH/fluorescence ISH (FISH) are standardised methods for detecting genetic alteration in clinical practice, and data on the correlation between these methods would be critical to determine the guideline for MET evaluation of cancer patients. However, to date, only a few small studies have compared IHC with FISH (Carracedo et al, 2009; Janjigian et al, 2011). In this study, we evaluated MET IHC and SISH concurrently in a large archival gastric cancer cohort. Direct comparison of the results revealed the positive correlation between high protein expression and increased GCN. Notably, all cases with GA $(n=13)$ showed MET protein overexpression (IHC $2+$ in 4 and IHC $3+$ in 9), which means that none of the IHC-negative cases had GA. Furthermore, all cases with IHC $3+$ had GA except 1 showing high polysomy. Indeed, tumour cells in that case possessed the average MET gene copy of 7.8, and therefore, this case could be categorised as GA when we adopted the ASCO/CAP guideline (2007) for HER2 assessment (Wolff et al, 2007). Also, in the cases of diffuse- or mixed-type cancers, MET-amplified tumours exactly corresponded with IHC $3+$ tumours. These findings suggest that strong expression of the MET protein $($ IHC $3+$ ) well represents GA, and thus, MET IHC can be an alternative method to replace FISH or SISH for patient selection for anti-MET therapy if GA is a major determinant of drug responsiveness. However, because a part of $M E T$-amplified cases presented IHC $2+$, SISH or FISH method would be necessary for the accurate assessment of GA status in the cases of IHC $2+$.

The positive correlation between increasing levels of MET protein expression and increased GCN indicates that the additive effect of gene copies such as polysomy of chromosome 7 and GA is an important mechanism of MET protein overexpression. However, a part of gastric carcinomas showed disomy while overexpressing MET protein, and on the contrary, a fraction of tumours with high polysomy did not show MET protein overexpression, suggesting that MET protein expression might also be controlled by mechanisms other than gene copy increase. One such mechanism is the transcriptional mechanism; earlier studies have reported that other oncogenes such as activated RAS can induce MET overexpression through transcriptional mechanism (Ivan et al, 1997; Furge et al, 2001).

This is the first study of MET GCN using SISH, a newly developed method. This assay has many advantages over FISH (Papouchado et al, 2010); and thus, HER2 SISH is widely used in current clinical practice. Because there were, however, no validation data on MET GCNs by SISH, we attempted to verify the SISH results by comparing with qPCR data. In this study, it was found that MET GCNs by SISH and qPCR were strongly correlated, although 3 of 13 SISH-determined, MET-amplified cases showed the relative GCN of $<2.0$ by qPCR. We guess that these discordant cases are due to intratumoural heterogeneity of MET GA. Indeed, some of the amplified cases showed the marked intratumoural heterogeneity by SISH within even a 2 -mm-sized tissue array core. These results indicate that MET SISH is an accurate and reliable method to examine the MET GCN, although further study such as comparison with FISH is required.

In spite of the great interest on MET, only a few studies have investigated the clinical implications of MET protein expression (Nakajima et al, 1999; Huang et al, 2001; Amemiya et al, 2002; Janjigian et al, 2011; Zhao et al, 2011; Toiyama et al, 2012) or copy number gain (Nakajima et al, 1999; Graziano et al, 2011; Lee et al, 2011; Lennerz et al, 2011). In this study, we assessed the impact of MET status on clinical outcome, and particularly performed survival analyses according to GCN examined by SISH in a large gastric cancer cohort. Whereas strong expression of MET (IHC $3+$ ) was associated with diffuse- or mixed-type cancers, advanced disease stage, and poor OS, moderate expression (IHC $2+$ ) was correlated with intestinal-type cancers, less advanced disease stage, and favourable prognosis. MET GA was not associated with the Lauren histologic subtype but tended to correlate with advanced disease stage. Also, gastric cancer patients with MET GA had a 

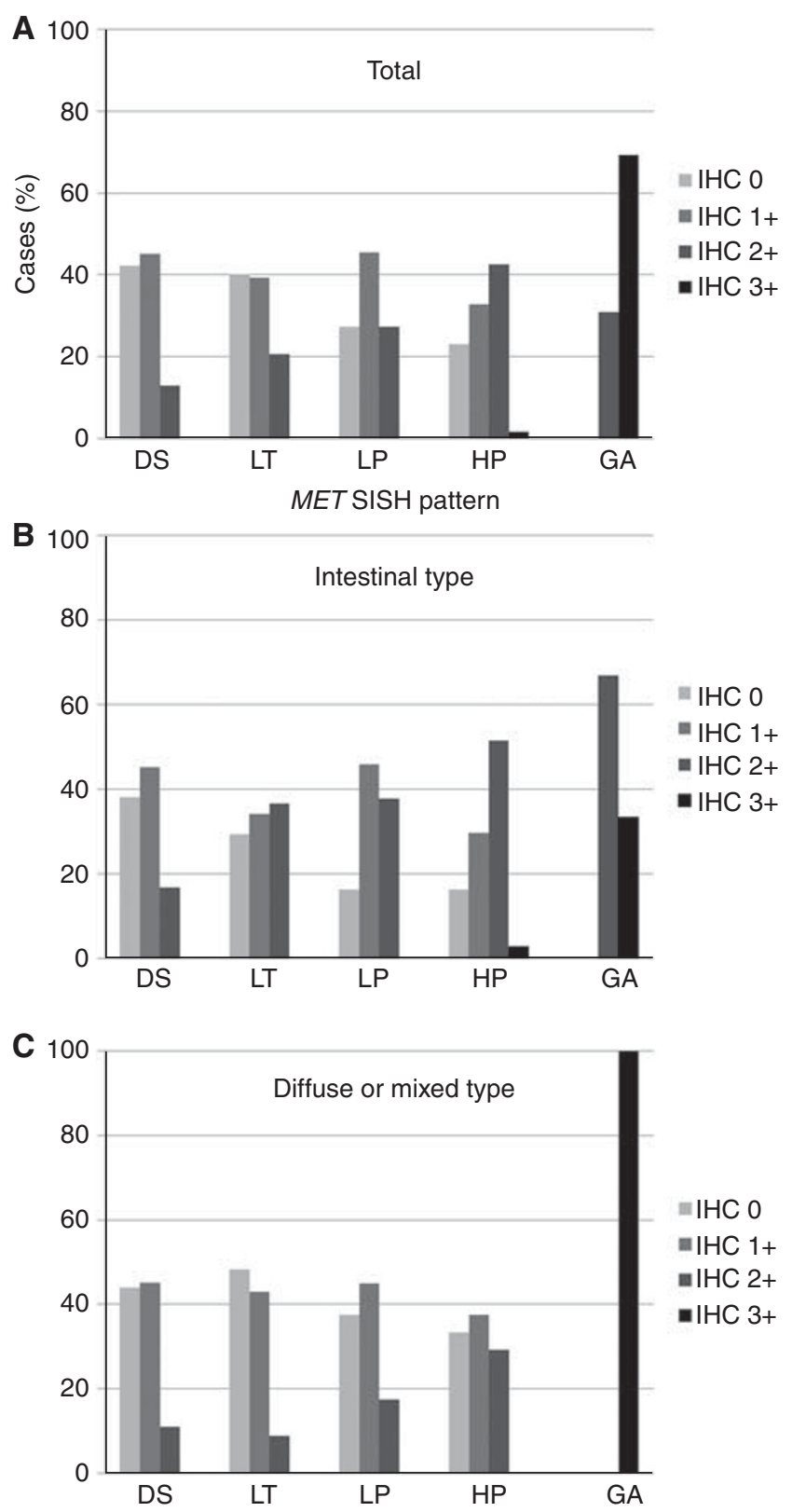

Figure 3 MET protein expression levels plotted according to the SISH patterns in total cases $(\mathbf{A} ; n=381)$, intestinal-type cancers $(\mathbf{B} ; n=163$, and diffuse- or mixed-type cancers $(\mathbf{C} ; n=218)$. The $\mathrm{IHC}$ score increased when SISH abnormalities became more severe irrespective of the Lauren histologic subtype. Specifically, the higher was the MET gene copy number, the lower was the frequency of $\mathrm{IHC} 0$ and the higher was that of $\mathrm{IHC} 2+$ and $\mathrm{IHC} 3+$. That of $\mathrm{IHC} I+$ was similar among the groups of SISH pattern. Notably, among 13 cases of gene amplification, 4 (30.8\%) and 9 (69.2\%) showed $\mathrm{IHC} 2+$ and $\mathrm{IHC} 3+$, respectively, whereas none had $\mathrm{IHC} 0$ or $\mathrm{HC} \mathrm{I}+$. In the gene amplification group of intestinal-type cancers, the frequency of $\mathrm{IHC} 2+$ was higher than that of $\mathrm{IHC} 3+(66.7 \%$ vs $33.3 \%$ ). In contrast, in cases of diffuse- or mixed-type cancers, cases showing gene amplification exactly corresponded with those with $\mathrm{HCC} 3+$ Abbreviations: DS = disomy; GA, gene amplification; HP = high polysomy; $\mathrm{LP}=$ low polysomy; $\mathrm{LT}=$ low trisomy.

shorter survival time irrespective of other classical prognostic factors, indicating that $M E T \mathrm{GA}$ is an independent negative prognostic factor in gastric cancer.

Subgroup analyses according to the disease stage elucidated that MET GA did not have an impact on prognosis in early TNM stage (stage I or II), unlike in advanced TNM stage (stage III or IV). All four tumours of early TNM stage showed both intestinal type and IHC $2+$, and three had a low level of MET GA. On the other hand, seven out of nine tumours of advanced TNM stage were diffuse or mixed type, and all showed both IHC $3+$ and a high level of GA. These findings suggest that there was a significant association between diffuse- or mixed-type cancers and a high level of GA, and that only a high level, but not a low level, of MET GA exerts a respectable influence on disease progression and patient survival. Also, the findings indicate that $M E T$ gene alteration can be acquired during the early phase of development of gastric cancer, especially intestinal-type cancer, and exaggerated during cancer progression.

An interesting finding is the different effect of high polysomy of chromosome 7 on patient survival according to the Lauren histologic subtype. Whereas intestinal-type cancers with high polysomy tended to show better prognosis than those with either SISH negative or GA, diffuse- or mixed-type cancers with high polysomy showed better prognosis than those with GA, but worse than those with SISH negative. In addition, high polysomy was much more common in intestinal-type cancers than in diffuse- or mixed-type cancers. Future studies need to explain these findings.

In this study, MET protein overexpression was found in $23.8 \%$, with a score of $2+$ in $21.5 \%$ and a score of $3+$ in $2.3 \%$. Previous studies describe much variable frequencies of MET protein overexpression (24-71\%) in gastric cancer (Nakajima et al, 1999; Huang et al, 2001; Amemiya et al, 2002; Janjigian et al, 2011; Zhao et al, 2011; Toiyama et al, 2012). The lack of standardisation in staining procedures and guidelines for interpretation of the MET IHC assessment as well as the difference in antibodies used may be the major reasons for the largely variable results across studies. Also, different sampling size and cohort characteristics might contribute to explain differences in the results. In this study, we immunostained using the Ventana monoclonal antibody (clone: SP44) and interpreted according to the DAKO HercepTest guideline for gastric cancer. The impact on the outcome by using different antibodies and scoring systems for immunohistochemical staining assessment of MET should be addressed in future comparative investigations.

Earlier results on $M E T$ GA frequency of gastric cancer were also much variable $(0-23 \%)$, and most of them are higher than the frequency of the present study $(3.4 \%)$. The reason seems to be mainly due to the difference in methodology (ISH, Southern blot, or qPCR). Indeed, whereas studies using Southern blot analyses or qPCR reported the quite high frequency of 9-23\% (Kuniyasu et al, 1992; Tsujimoto et al, 1997; Nessling et al, 1998; Nakajima et al, 1999; Sakakura et al, 1999; Graziano et al, 2011; Lee et al, 2011), those using FISH described the frequency of none (Janjigian et al, 2011), 2.4\% (Lennerz et al, 2011), and 3.9\% (Hara et al, 1998) of gastric cancer, which is similar to that of our study. Southern blot analysis and GPCR have the high chance of overestimating the incidence of MET GA because it cannot discriminate polysomy from GA. Nowadays, FISH or SISH using ISH technology has replaced Southern blot analysis or GPCR because of more accurate information on the GCN of tumour cells in tissue sections.

This study did not attempt to reveal the association of MET GCN or protein expression with the responsiveness of MET inhibitors. However, our findings on the correlation between MET protein expression and GCN and their clinical implications would be an important basis in future studies about patient selection for antiMET therapy. Clinical and pathologic parameters might have a role in the identification of the group of patients most likely to benefit from anti-MET therapy, and future studies need to evaluate the direct correlation between the parameters and the drug responsiveness to determine the optimal target population.

In conclusion, we investigated MET GCN and protein expression using SISH and IHC, respectively, in a large series of gastric cancer. The significant correlation between increased GCN and high 
A

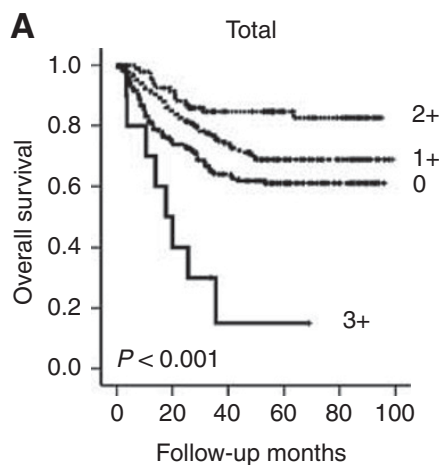

D

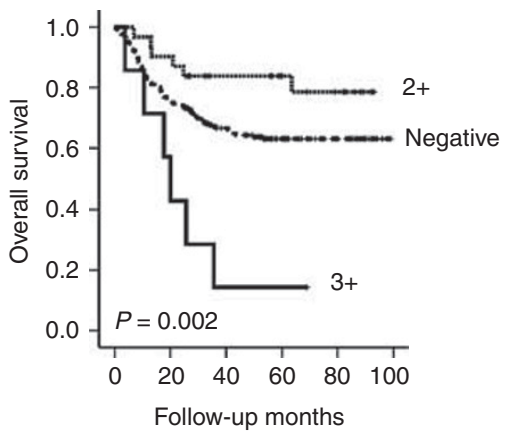

B

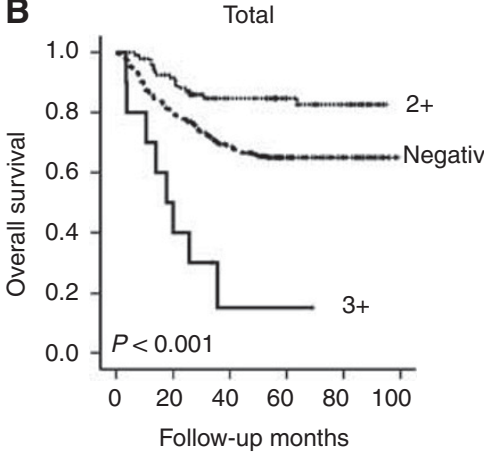

$\mathbf{E}$

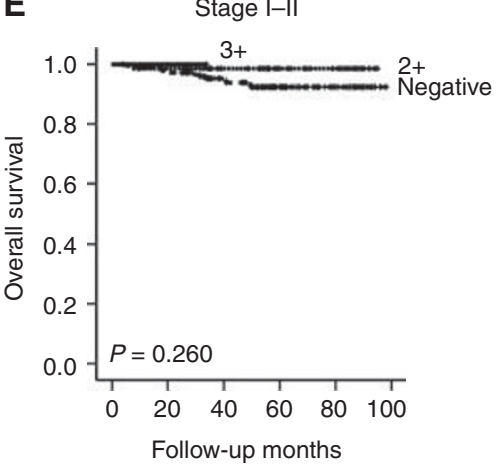

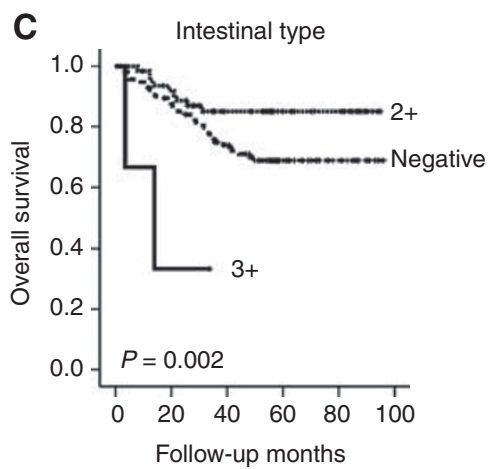

$\mathbf{F}$

Stage III-IV

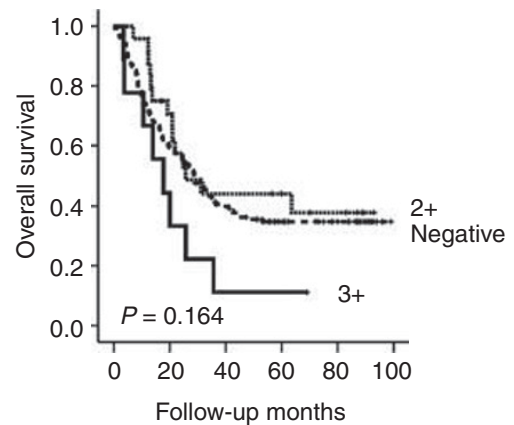

Figure 4 Kaplan-Meier curves for overall survival according to the level of MET protein expression. Whereas the group of IHC $3+$ had a shorter survival time than that of $\mathrm{IHC}$ negative, the group of $\mathrm{IHC} 2+$ had a longer survival time ( $\mathbf{A}$ and $\mathbf{B})$, which was independent of the Lauren histologic subtype (C and D). In the subgroup analyses of disease stage, there was no difference in survival among the three IHC score groups in stages I-II (E). In stages III-IV, survival differences were found among the $\mathrm{IHC}$ score groups, although they did not reach statistical significances $(\mathbf{F})$.

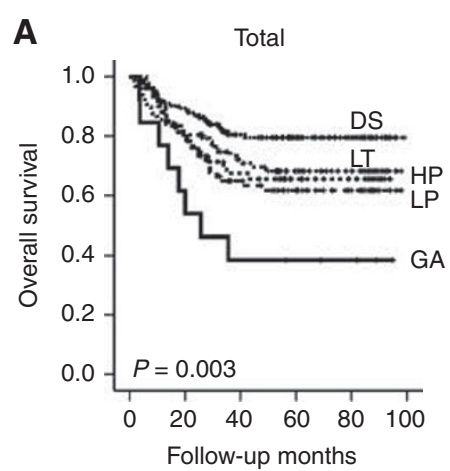

D

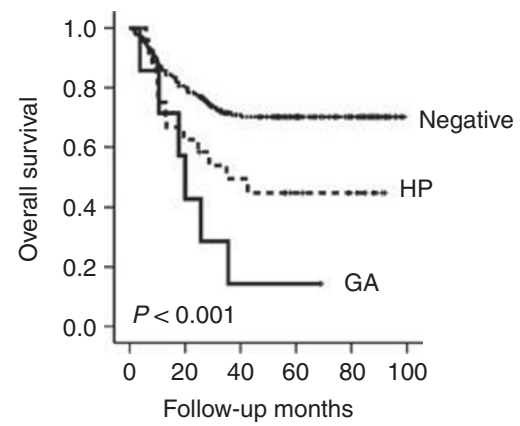

B

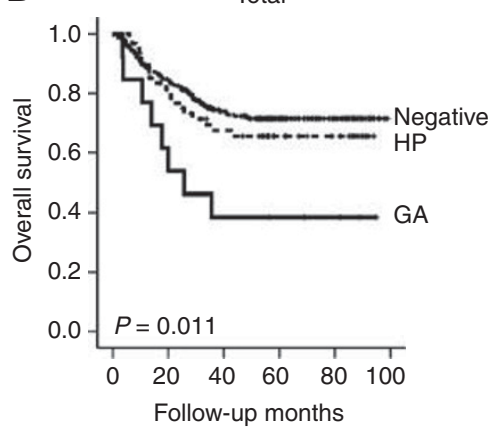

E

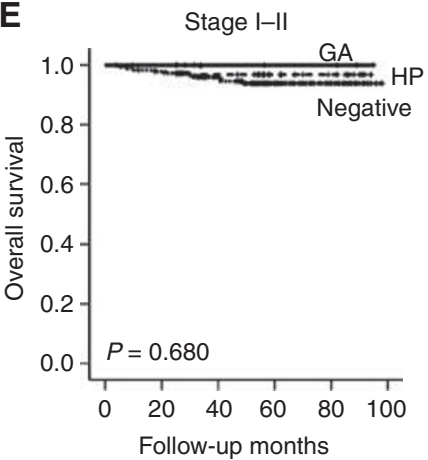

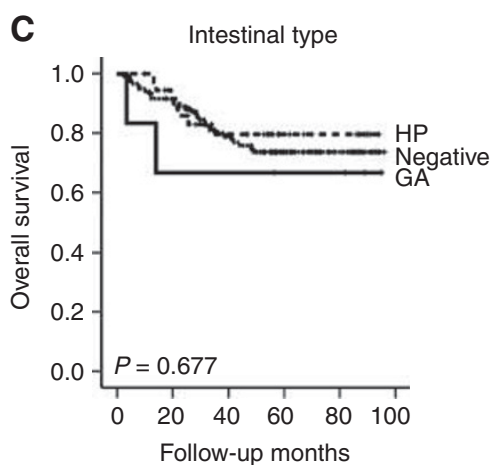

$\mathbf{F}$

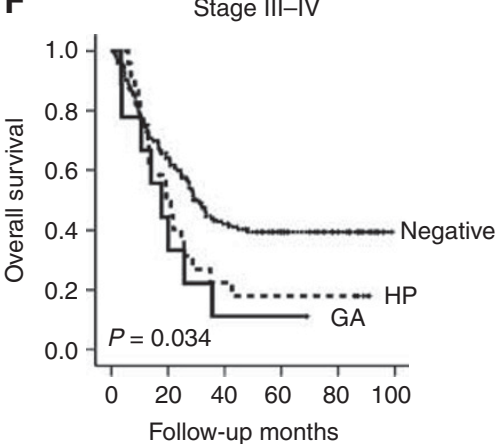

Figure 5 Kaplan-Meier curves for overall survival according to the level of MET gene copy number. Overall survival times were found to decrease with increasing gene copy number $(\mathbf{A}$ and $\mathbf{B})$, but the group of high polysomy tended to have a longer survival time than that of low polysomy although it was not a statistically significant difference. In the subgroup analysis of intestinal-type cancers, the high polysomy group tended to have a longer survival time than the SISHnegative group, although it was not statistically significant $(\mathbf{C})$. On the other hand, in the subgroup of diffuse- or mixed-type cancers, survival times became significantly shorter as the MET gene copy number increased (D). In the subgroup analysis of stage I and II disease, survival times were not different according to the level of gene copy number $(\mathbf{E})$. However, when survival analysis was limited to patients with stage III and IV disease, survival times became significantly shorter as the MET gene copy number increased $(\mathbf{F})$. 
protein expression of MET and the approximate correspondence of IHC $3+$ and GA suggest that MET IHC could be a primary screening test for patient selection for anti-MET therapy if GA is a major determinant of drug responsiveness. In addition, our finding that GA and strong expression of MET were negative prognostic factors indicates that anti-MET therapy is a very promising modality in the field of adjuvant treatment for gastric cancer patients.

\section{REFERENCES}

Amemiya H, Kono K, Itakura J, Tang RF, Takahashi A, An FQ, Kamei S, Iizuka H, Fujii H, Matsumoto Y (2002) c-Met expression in gastric cancer with liver metastasis. Oncology 63: 286-296

Bang YJ, Van Cutsem E, Feyereislova A, Chung HC, Shen L, Sawaki A, Lordick F, Ohtsu A, Omuro Y, Satoh T, Aprile G, Kulikov E, Hill J, Lehle M, Ruschoff J, Kang YK (2010) Trastuzumab in combination with chemotherapy vs chemotherapy alone for treatment of HER2-positive advanced gastric or gastro-oesophageal junction cancer (ToGA): a phase 3, open-label, randomised controlled trial. Lancet 376: 687-697

Cappuzzo F, Marchetti A, Skokan M, Rossi E, Gajapathy S, Felicioni L, del Grammastro M, Sciarrotta MG, Buttitta F, Incarbone M, Toschi L, Finocchiaro G, Destro A, Terracciano L, Roncalli M, Alloisio M, Santoro A, Varella-Garcia M (2009) Increased MET gene copy number negatively affects survival of surgically resected non-small-cell lung cancer patients. J Clin Oncol 27: 1667-1674

Cappuzzo F, Hirsch FR, Rossi E, Bartolini S, Ceresoli GL, Bemis L, Haney J, Witta S, Danenberg K, Domenichini I, Ludovini V, Magrini E, Gregorc V, Doglioni C, Sidoni A, Tonato M, Franklin WA, Crino L, Bunn PA, Varella-Garcia M (2005) Epidermal growth factor receptor gene and protein and gefitinib sensitivity in non-small-cell lung cancer. J Natl Cancer Inst 97: 643-655

Carracedo A, Egervari K, Salido M, Rojo F, Corominas JM, Arumi M, Corzo C, Tusquets I, Espinet B, Rovira A, Albanell J, Szollosi Z, Serrano S, Solé F (2009) FISH and immunohistochemical status of the hepatocyte growth factor receptor (c-Met) in 184 invasive breast tumors. Breast Cancer Res 11: 402

Cecchi F, Rabe DC, Bottaro DP (2010) Targeting the HGF/Met signalling pathway in cancer. Eur J Cancer 46: 1260-1270

Fenoglio-Preiser C, Carneiro F, Correa P, Guilford P, Lambert R, Megraud F, Munos N, Powell SM, Rugge M, Sasako M, Stolte M, Watanabe H (2000) Gastric carcinoma. In World Health Organization Classification of Tumors; Pathology and Genetics of Tumors of the Digestive System, Hamilton SR, Aaltonen LA (eds) pp 39-52. IARC Press: Lyon

Furge KA, Kiewlich D, Le P, Vo MN, Faure M, Howlett AR, Lipson KE, Woude GF, Webb CP (2001) Suppression of Ras-mediated tumorigenicity and metastasis through inhibition of the Met receptor tyrosine kinase. Proc Natl Acad Sci USA 98: 10722-10727

Go H, Jeon YK, Park HJ, Sung SW, Seo JW, Chung DH (2010) High MET gene copy number leads to shorter survival in patients with non-small cell lung cancer. J Thorac Oncol 5: 305-313

Graziano F, Galluccio N, Lorenzini P, Ruzzo A, Canestrari E, D’Emidio S, Catalano V, Sisti V, Ligorio C, Andreoni F, Rulli E, Di Oto E, Fiorentini G, Zingaretti C, De Nictolis M, Cappuzzo F, Magnani M (2011) Genetic activation of the MET pathway and prognosis of patients with high-risk, radically resected gastric cancer. J Clin Oncol 29: 4789-4795

Hara T, Ooi A, Kobayashi M, Mai M, Yanagihara K, Nakanishi I (1998) Amplification of c-myc, K-sam, and c-met in gastric cancers: detection by fluorescence in situ hybridization. Lab Invest 78: 1143-1153

Huang TJ, Wang JY, Lin SR, Lian ST, Hsieh JS (2001) Overexpression of the c-met protooncogene in human gastric carcinoma - correlation to clinical features. Acta Oncol 40: 638-643

Ivan M, Bond JA, Prat M, Comoglio PM, Wynford-Thomas D (1997) Activated ras and ret oncogenes induce over-expression of c-met (hepatocyte growth factor receptor) in human thyroid epithelial cells. Oncogene 14: 2417-2423

Janjigian YY, Tang LH, Coit DG, Kelsen DP, Francone TD, Weiser MR, Jhanwar SC, Shah MA (2011) MET expression and amplification in patients with localized gastric cancer. Cancer Epidemiol Biomarkers Prev 20: $1021-1027$

Kuniyasu H, Yasui W, Kitadai Y, Yokozaki H, Ito H, Tahara E (1992) Frequent amplification of the c-met gene in scirrhous type stomach cancer. Biochem Biophys Res Commun 189: 227-232

\section{ACKNOWLEDGEMENTS}

This study was supported by a grant from the National R\&D Program for Cancer Control, Ministry for Health and Welfare, Republic of Korea (101146)

Supplementary Information accompanies the paper on British Journal of Cancer website (http://www.nature.com/bjc)

Lee HS, Lee HK, Kim HS, Yang HK, Kim YI, Kim WH (2001) MUC1, MUC2, MUC5AC, and MUC6 expressions in gastric carcinomas: their roles as prognostic indicators. Cancer 92: 1427-1434

Lee J, Seo JW, Jun HJ, Ki CS, Park SH, Park YS, Lim HY, Choi MG, Bae JM, Sohn TS, Noh JH, Kim S, Jang HL, Kim JY, Kim KM, Kang WK, Park JO (2011) Impact of MET amplification on gastric cancer: possible roles as a novel prognostic marker and a potential therapeutic target. Oncol Rep 25: 1517-1524

Lennerz JK, Kwak EL, Ackerman A, Michael M, Fox SB, Bergethon K, Lauwers GY, Christensen JG, Wilner KD, Haber DA, Salgia R, Bang YJ, Clark JW, Solomon BJ, Iafrate AJ (2011) MET amplification identifies a small and aggressive subgroup of esophagogastric adenocarcinoma with evidence of responsiveness to crizotinib. J Clin Oncol 29: 4803-4810

Liu X, Newton RC, Scherle PA (2010) Developing c-MET pathway inhibitors for cancer therapy: progress and challenges. Trends $\mathrm{Mol}$ Med 16: 37-45

Ma PC, Kijima T, Maulik G, Fox EA, Sattler M, Griffin JD, Johnson BE, Salgia R (2003) c-MET mutational analysis in small cell lung cancer: novel juxtamembrane domain mutations regulating cytoskeletal functions. Cancer Res 63: 6272-6281

Miller CT, Lin L, Casper AM, Lim J, Thomas DG, Orringer MB, Chang AC, Chambers AF, Giordano TJ, Glover TW, Beer DG (2005) Genomic amplification of MET with boundaries within fragile site FRA7G and upregulation of MET pathways in esophageal adenocarcinoma. Oncogene 25: $409-418$

Nakajima M, Sawada H, Yamada Y, Watanabe A, Tatsumi M, Yamashita J, Matsuda M, Sakaguchi T, Hirao T, Nakano H (1999) The prognostic significance of amplification and overexpression of c-met and c-erb B-2 in human gastric carcinomas. Cancer 85: 1894-1902

Nessling M, Solinas-Toldo S, Wilgenbus KK, Borchard F, Lichter P (1998) Mapping of chromosomal imbalances in gastric adenocarcinoma revealed amplified protooncogenes MYCN, MET, WNT2, and ERBB2. Genes Chromosomes Cancer 23: 307-316

Papouchado BG, Myles J, Lloyd RV, Stoler M, Oliveira AM, Downs-Kelly E, Morey A, Bilous M, Nagle R, Prescott N, Wang L, Dragovich L, McElhinny A, Garcia CF, Ranger-Moore J, Free H, Powell W, Loftus M, Pettay J, Gaire F, Roberts C, Dietel M, Roche P, Grogan T, Tubbs R (2010) Silver in situ hybridization (SISH) for determination of HER2 gene status in breast carcinoma: comparison with FISH and assessment of interobserver reproducibility. Am J Surg Pathol 34: 767-776

Sakakura C, Mori T, Sakabe T, Ariyama Y, Shinomiya T, Date K, Hagiwara A, Yamaguchi T, Takahashi T, Nakamura Y, Abe T, Inazawa J (1999) Gains, losses, and amplifications of genomic materials in primary gastric cancers analyzed by comparative genomic hybridization. Genes Chromosomes Cancer 24: 299-305

Samuelson E, Levan K, Adamovic T, Levan G, Horvath G (2008) Recurrent gene amplifications in human type I endometrial adenocarcinoma detected by fluorescence in situ hybridization. Cancer Genet Cytogenet 181: $25-30$

Schmidt L, Duh FM, Chen F, Kishida T, Glenn G, Choyke P, Scherer SW, Zhuang Z, Lubensky I, Dean M, Allikmets R, Chidambaram A, Bergerheim UR, Feltis JT, Casadevall C, Zamarron A, Bernues M, Richard S, Lips CJ, Walther MM, Tsui LC, Geil L, Orcutt ML, Stackhouse T, Lipan J, Slife L, Brauch H, Decker J, Niehans G, Hughson MD, Moch H, Storkel S, Lerman MI, Linehan WM, Zbar B (1997) Germline and somatic mutations in the tyrosine kinase domain of the MET protooncogene in papillary renal carcinomas. Nat Genet 16: 68-73

Smolen GA (2006) Amplification of MET may identify a subset of cancers with extreme sensitivity to the selective tyrosine kinase inhibitor PHA-665752. Proc Natl Acad Sci USA 103: 2316-2321

Toiyama Y, Yasuda H, Saigusa S, Matushita K, Fujikawa H, Tanaka K, Mohri Y, Inoue Y, Ajay G, Kusunoki M (2012) Co-expression of 
hepatocyte growth factor (HGF) and c-Met predicts peritoneal dissemination established by autocrine $\mathrm{HGF} / \mathrm{c}$-Met signaling in gastric cancer. Int J Cancer 130: 2912-2921

Tsujimoto H, Sugihara H, Hagiwara A, Hattori T (1997) Amplification of growth factor receptor genes and DNA ploidy pattern in the progression of gastric cancer. Virchows Arch 431: 383-389

Wolff AC, Hammond ME, Schwartz JN, Hagerty KL, Allred DC, Cote RJ, Dowsett M, Fitzgibbons PL, Hanna WM, Langer A, McShane LM, Paik S, Pegram MD, Perez EA, Press MF, Rhodes A, Sturgeon C, Taube SE, Tubbs R, Vance GH, van de Vijver M, Wheeler TM, Hayes DF (2007) American Society of Clinical Oncology/College of American Pathologists guideline recommendations for human epidermal growth factor receptor 2 testing in breast cancer. J Clin Oncol 25: 118-145

Yap TA, Olmos D, Brunetto AT, Tunariu N, Barriuso J, Riisnaes R, Pope L, Clark J, Futreal A, Germuska M, Collins D, deSouza NM, Leach MO, Savage RE, Waghorne C, Chai F, Garmey E, Schwartz B, Kaye SB, de Bono JS (2011) Phase I trial of a selective c-MET inhibitor ARQ 197 incorporating proof of mechanism pharmacodynamic studies. J Clin Oncol 29: 1271-1279

Zhao J, Zhang X, Xin Y (2011) Up-regulated expression of Ezrin and c-Met proteins are related to the metastasis and prognosis of gastric carcinomas. Histol Histopathol 26: 1111-1120

This work is published under the standard license to publish agreement. After 12 months the work will become freely available and the license terms will switch to a Creative Commons Attribution-NonCommercial-Share Alike 3.0 Unported License. 